\title{
Physical Properties of Self-Assembled Porous Alumina Structures Filled with lodine
}

\author{
Natalia Alekseeva ${ }^{1}$, Grigory Cema ${ }^{1}$, Dmitry Podorozhkin ${ }^{2}$, \\ Vladimir Solovyev $^{1, *}$, Sergey Trifonov ${ }^{1}$ and Victor Veisman ${ }^{1}$ \\ ${ }^{1}$ Department of Physics, Faculty of Physics and Mathematics, Pskov State \\ University, Lenin Square 2, Pskov 180000, Russia \\ ${ }^{2}$ Resource Centre for Diagnosis of Functional Materials in Medicine, \\ Pharmacology and Nanoelectronics of St. Petersburg State University, \\ St. Petersburg, Petrodvorets 198504, Russia \\ *Corresponding author: solovyev_v55@mail.ru
}

Received 10 September 2014; Accepted 18 February 2015; Publication 31 March 2015

\begin{abstract}
Self-assembled porous alumina structures (por $\mathrm{Al}_{2} \mathrm{O}_{3}$ ) were prepared by twostep anodization process and characterized by scanning electron microscopy. Filling quasi one-dimensional parallel nanochannels of por $\mathrm{Al}_{2} \mathrm{O}_{3}$ host matrix with iodine guest substance by vapor phase adsorption method resulted in the formation of I/por $\mathrm{Al}_{2} \mathrm{O}_{3}$ nanocomposite. Electrical properties of these nanocomposite samples were studied by alternating-current measurements at a frequency of $1 \mathrm{kHz}$. Ellipsometric measurements were carried out in the spectral range 350-1000 nm. Structural transition of iodine species from the chain structures to molecular iodine was found in $\mathrm{I} /$ por $\mathrm{Al}_{2} \mathrm{O}_{3}$ nanocomposite at $\sim 70{ }^{\circ} \mathrm{C}$.
\end{abstract}

Keywords: porous alumina, iodine nanoparticles, nanocomposite, electrical conduction, ellipsometry, phase transition.

Journal of Self-Assembly and Molecular Electronics, Vol. 2, 27-40.

doi: 10.13052/jsame2245-4551.212

(C) 2015 River Publishers. All rights reserved. 


\section{Introduction}

In the last decades I/AFI composites prepared by infiltration of the quasi onedimensional nanochannels of AFI zeolite-like microporous aluminophosphate host matrix [1] with iodine guest substance (semiconductor with $p$-type conductivity) were thoroughly studied by polarized optical absorption and Raman spectroscopy, thermal gravimetry and differential scanning calorimetry [2-4] as well as by electrical methods [5]. Iodine species inserted inside the AFI zeolite-like framework were proposed to be a prospective candidate for iodine Raman laser design [4]. The most striking feature of nanostructured iodine behavior in AFI channels with inner diameter $0.73 \mathrm{~nm}$ is probably the first-order phase transition from the chain structures to the molecular species at $t_{0} \approx 70{ }^{\circ} \mathrm{C}$ which was found first by optical characterization and phase dynamics [2-4]. Our direct-current electrical measurements [5] proved the occurrence of the iodine species phase transition from chain structures to molecular iodine near $70{ }^{\circ} \mathrm{C}$. We have interpreted the pronounced peculiarity in the temperature dependence of direct-current electrical conduction measured along the channels as the result of semiconductor-to-insulator structural transition in iodine species in AFI zeolite-like porous matrix (i.e., posistor effect in I/AFI composite nanostructured material).

Porous anodic alumina (por $\mathrm{Al}_{2} \mathrm{O}_{3}$ ) with straight and parallel pores could be considered a next candidate for quasi one-dimensional iodine chain formation by matrix method. The structure of this material has been known since the early 1900s; it was widely used to protect and to decorate the aluminum surface or to make inorganic membranes.

In recent years porous anodic alumina has become a popular template system for the synthesis of various nanostructures [6]. Many materials including nanowires, nanotubes and nanodot arrays have been fabricated by deposition of various metals, semiconductors, oxides and polymers inside the pores of anodic alumina. In this work electrical and some optical properties of $\mathrm{I} /$ por $\mathrm{Al}_{2} \mathrm{O}_{3}$ were studied.

In 1995 Masuda and Fukuda developed a two-step process to achieve a uniform, closely packed honeycomb structure [7]. The method discovered by Masuda et al. relies on self-ordering of pores at the bottom of porous alumina channels after a long first-anodization step under appropriate conditions, known as 'self-ordering regimes'. The driving force for self-assembly has been attributed to the repulsive forces between neighboring pores caused by mechanical stress at the metal/oxide interface $[8,9]$. Hexagonally arranged 


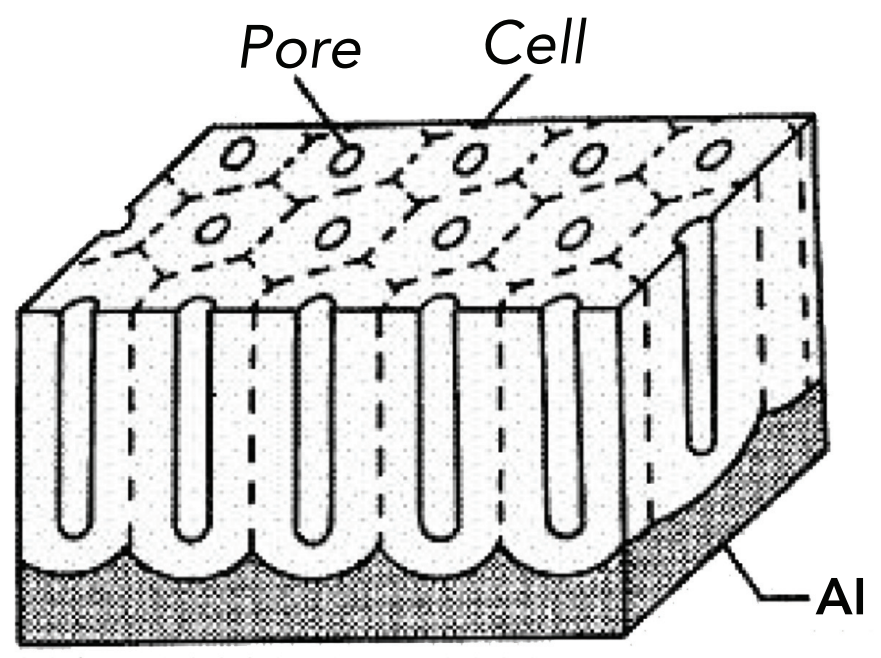

Figure 1 Schematic drawing of porous alumina.

arrays with straight and parallel pores can be obtained by this method (Figure 1).

\section{Experimental Procedures}

Two-step anodization was done using experimental setup described in [10]. This process is illustrated in Figure 2.

Firstly, aluminum sheet of $0.5 \mathrm{~mm}$ thick was degreased in acetone and mechanically polished.

Then anodization was performed at $40 \mathrm{~V}$ in $0.3 \mathrm{M}$ oxalic acid at $8{ }^{\circ} \mathrm{C}$ for 5 hours. After the first step of anodization the oxide layer was chemically removed in mixture of $20 \mathrm{~g} / \mathrm{l} \mathrm{CrO}$ and $35 \mathrm{ml} / / \mathrm{H}_{3} \mathrm{PO}_{4}$ at $80^{\circ} \mathrm{C}$. The second anodization step was performed for 5.5 hours under the same conditions as those used in the first step.

Typical AFM-images of the aluminium surface after removal of the porous oxide as well as those of the porous alumina after the second anodization step were demonstrated in [10]. Porous alumina template samples under study were characterized by Field Emission Scanning Electronic Microscope (FESEM) ZEISS MERLIN in Interdisciplinary Resource Center for Nanotechnology of St. Petersburg State University. 


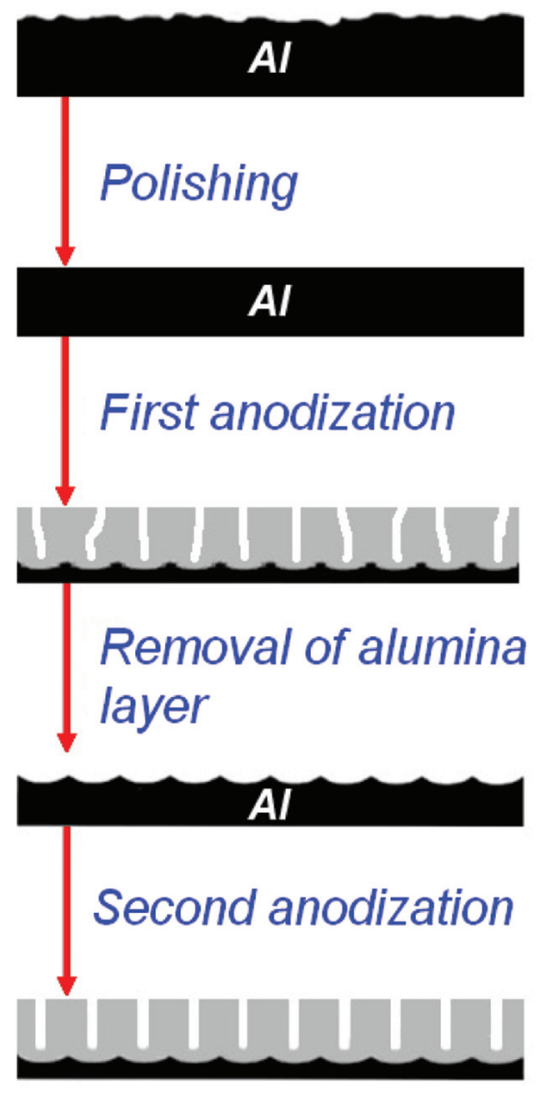

Figure 2 Two-step anodization.

To incorporate iodine species into quasi one-dimensional parallel nanochannels of por $\mathrm{Al}_{2} \mathrm{O}_{3}$ host matrix, vapor phase adsorption at $175{ }^{\circ} \mathrm{C}$ under iodine vapor pressure $\sim 140 \mathrm{kPa}$ for $7 \mathrm{~h}$ was used, resulting in the $\mathrm{I} /$ por $\mathrm{Al}_{2} \mathrm{O}_{3}$ nanocomposite formation.

Dielectric measurements of samples were carried out at the frequency of $1 \mathrm{kHz}$ by an E7-13 impedance meter. The temperature dependences of sample capacity $\mathrm{C}(\mathrm{t})$ and sample conduction $\mathrm{G}(\mathrm{t})$ were measured upon continuous warming with a heating rate of 1 to 2 degrees per minute.

Some optical properties of the samples under study were characterized by the spectroscopic ellipsometer "Ellips-1891" (Novosibirsk), working in the static photometric mode without any rotating elements or modulators $[11,12]$. 


\section{Results \& Discussion}

Although the sample preparation conditions were near the self ordered regime, porous alumina template under study did not look like the highly ordered ideal hexagonal structure (Figure 3), probably, due to the effect of impurities, defects, and grain-size of the starting Al sheet on the degree of pore system regularity and uniformity [6]. From the SEM images one can estimate the mean pore diameter $D_{p} \approx 55 \mathrm{~nm}$ and the density of pores $x \approx 2 \times 10^{10}$ pores $/ \mathrm{cm}^{2}$. The parallel alignment of the pores in the sample prepared under the similar experimental conditions was proved in [6] by cross section SEM images.

Figures 4 and 5 demonstrate typical spectral dependences of ellipsometric parameter $\Psi(\lambda)$ and those of refractive index $n(\lambda)$ for por $\mathrm{Al}_{2} \mathrm{O}_{3}$ host matrix and I/por $\mathrm{Al}_{2} \mathrm{O}_{3}$ nanocomposite. Pronounced oscillations could be observed in the long - wavelength region, where the films under study are rather transparent. We suppose that this effect is probably due to the interference of light in thin films. In this case one should calculate the por $\mathrm{Al}_{2} \mathrm{O}_{3}$ film thickness $d$ from the equation

$$
m=2 d \sqrt{n^{2}-\sin ^{2} \theta} \cdot \frac{1}{\lambda}
$$

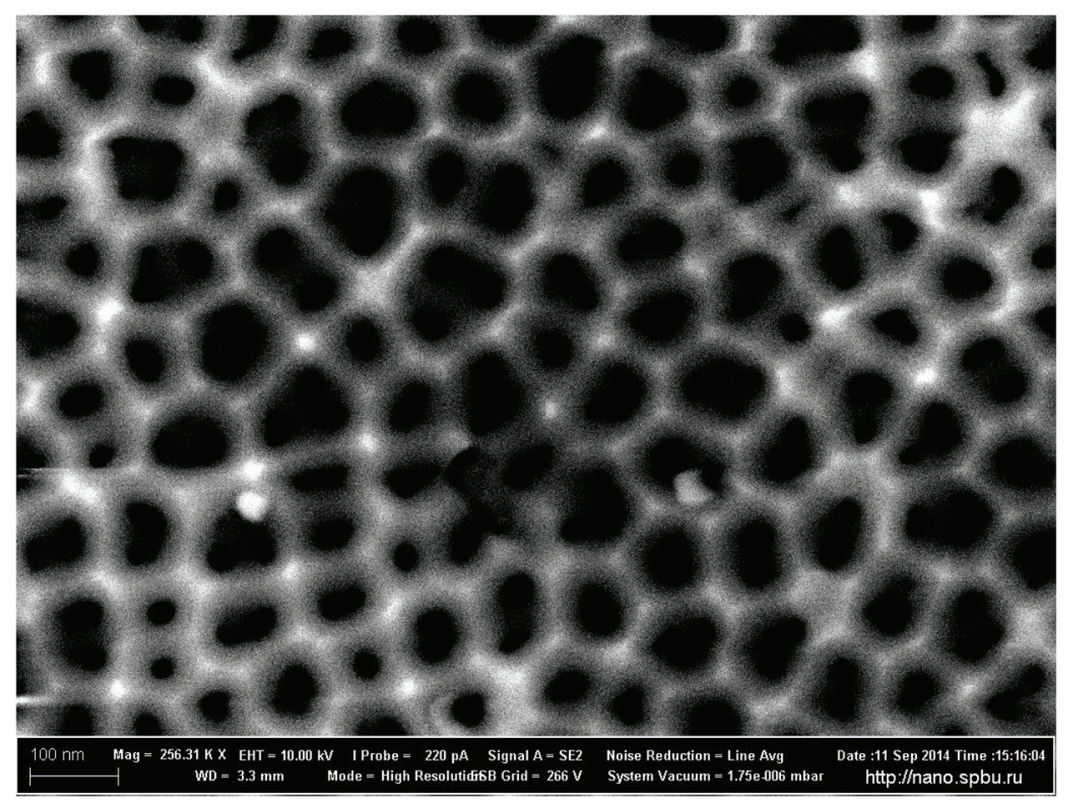

Figure 3 SEM image of por $\mathrm{Al}_{2} \mathrm{O}_{3}$ template under study. 


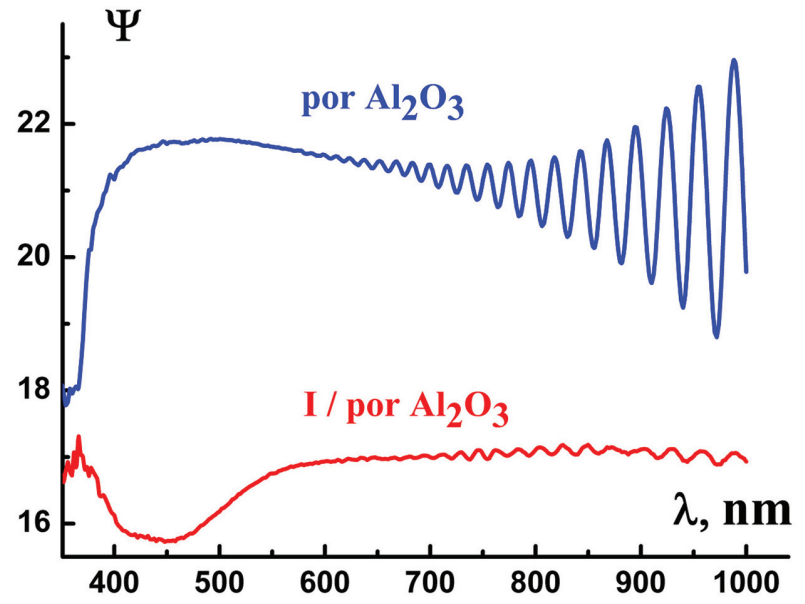

Figure 4 Ellipsometric parameters $\Psi(\lambda)$ of por $\mathrm{Al}_{2} \mathrm{O}_{3}$ host matrix and I/por $\mathrm{Al}_{2} \mathrm{O}_{3}$ nanocomposite.

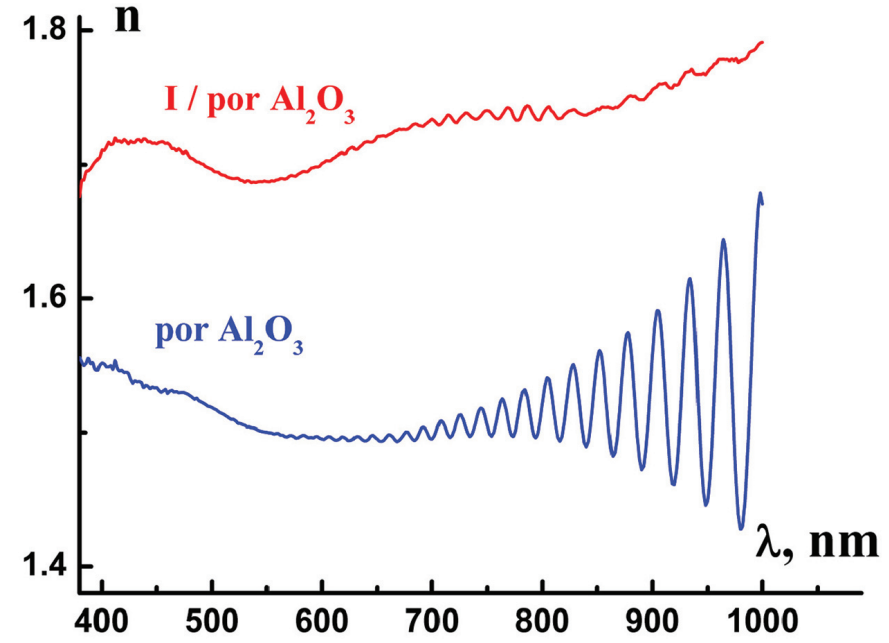

Figure 5 Refractive index $n(\lambda)$ of por $\mathrm{Al}_{2} \mathrm{O}_{3}$ host matrix and I/por $\mathrm{Al}_{2} \mathrm{O}_{3}$ nanocomposite calculated from ellipsometric data.

where $\vartheta$ is the angle of light incidence, $n \approx 1.5$ is the effective refractive index, $m$ is an integer (order of the interference maximum), $\lambda$ is the wavelength at this interference maximum. Our experimental data prove this assumption: typical straight lines $m=\mathrm{f}\left(\lambda^{-1}\right)$ plotted in Figure 6, are for different angles of light incidence. Thus, according to our ellipsometric data, por $\mathrm{Al}_{2} \mathrm{O}_{3}$ film thickness 


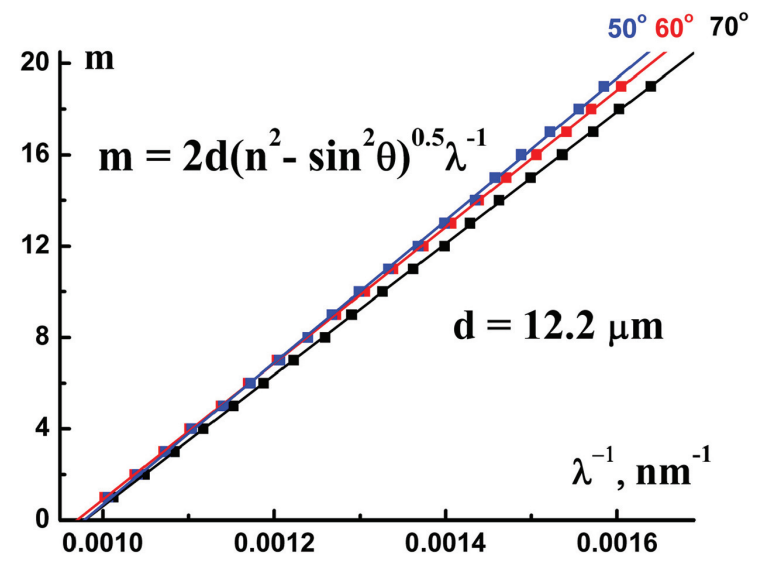

Figure 6 Plots $m=\mathrm{f}\left(\lambda^{-1}\right)$ for three different angles of light incidence $\vartheta ; m$ is an integer (order of the interference maximum), $\lambda$ is the wavelength at this interference maximum.

$d$ is $(12.2 \pm 0.1) \mu \mathrm{m}$. This value agrees with the estimation based on the product of film growth rate $(2 \mu \mathrm{m} / \mathrm{h}$ [13]) and the second anodization step duration $(5.5 \mathrm{~h})$. Thus, maximum value of the aspect ratio for the nanopores in the por $\mathrm{Al}_{2} \mathrm{O}_{3}$ film under study is $d / D_{p} \approx 2 \times 10^{2}$ (in AFI zeolite-like single crystals this value could be about two orders of magnitude higher).

The value of refractive index $n_{\text {eff }}$ can be also estimated using the effective medium approximation:

$$
n_{e f f}^{2}=f n_{1}^{2}+(1-f) f n_{2}^{2},
$$

where $f \approx \frac{\pi D_{p}^{2} x}{4} \approx 0.475$ is the volume fraction of air voids in the por $\mathrm{Al}_{2} \mathrm{O}_{3}$ matrix, $n_{1}=n_{\text {air }}, n_{2} \approx 1.77$ is the refractive index of bulk $\mathrm{Al}_{2} \mathrm{O}_{3}$ [14], so we have $n_{\text {eff }} \approx 1.5$ in the agreement with the index extracted from the ellipsometric data. It should be also noted that there exists a marked difference $\Delta n \approx 0.2$ between the effective refractive index of the $\mathrm{I} /$ por $\mathrm{Al}_{2} \mathrm{O}_{3}$ nanocomposite and that of the por $\mathrm{Al}_{2} \mathrm{O}_{3}$ matrix in the visible spectrum (Figure 5) due to the infiltration of the guest substance (iodine) with high refractive index into the channels of the host matrix (por $\mathrm{Al}_{2} \mathrm{O}_{3}$ ).

The measured conduction $\mathrm{G}$ value of the $\mathrm{I} /$ por $\mathrm{Al}_{2} \mathrm{O}_{3}$ nanocomposite is $10^{2}$ or $10^{3}$ times larger than that of the host matrix, its temperature dependence $\mathrm{G}(\mathrm{t})$ demonstrating distinct leap at $t_{0} \approx 70{ }^{\circ} \mathrm{C}$ (Figure 7). This temperature was previously attributed to the phase transition of iodine species in the quasi one-dimensional nanochannels of AFI zeolite-like nanoporous aluminophosphate from the chain structures to molecular iodine (see Section 
34 N. Alekseeva et al.

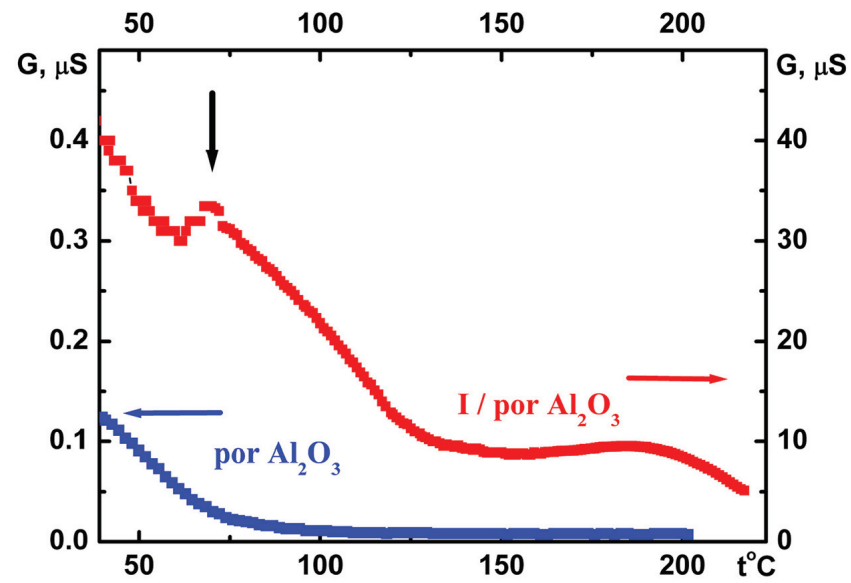

Figure 7 Temperature dependences of the alternating-current $(1 \mathrm{kHz})$ electrical conduction $\mathrm{G}(\mathrm{t})$ for por $\mathrm{Al}_{2} \mathrm{O}_{3}$ host matrix and I/por $\mathrm{Al}_{2} \mathrm{O}_{3}$ nanocomposite. Vertical arrow shows the temperature of phase (structural) transition.

1). However, it should be emphasized that the I/AFI nanocomposite displays much more pronounced jump in the temperature dependence $\mathrm{G}(\mathrm{t})$ (Figure 8) at $\sim 70{ }^{\circ} \mathrm{C}$ than the I/por $\mathrm{Al}_{2} \mathrm{O}_{3}$ nanocomposite does (Figure 7). It could be due to more regular arrangement and better alignment of iodine chains inside the narrow channels of AFI zeolite-like crystalline nanoporous matrix

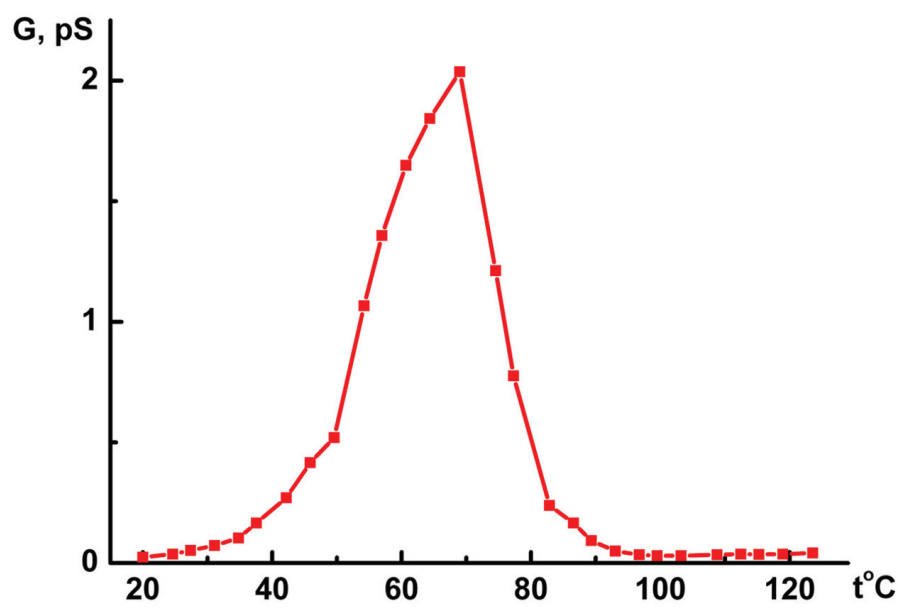

Figure 8 Temperature dependence of the direct-current electrical conduction $\mathrm{G}(\mathrm{t})$ measured along the channels of I/AFI nanocomposite with low iodine concentration [5]. 


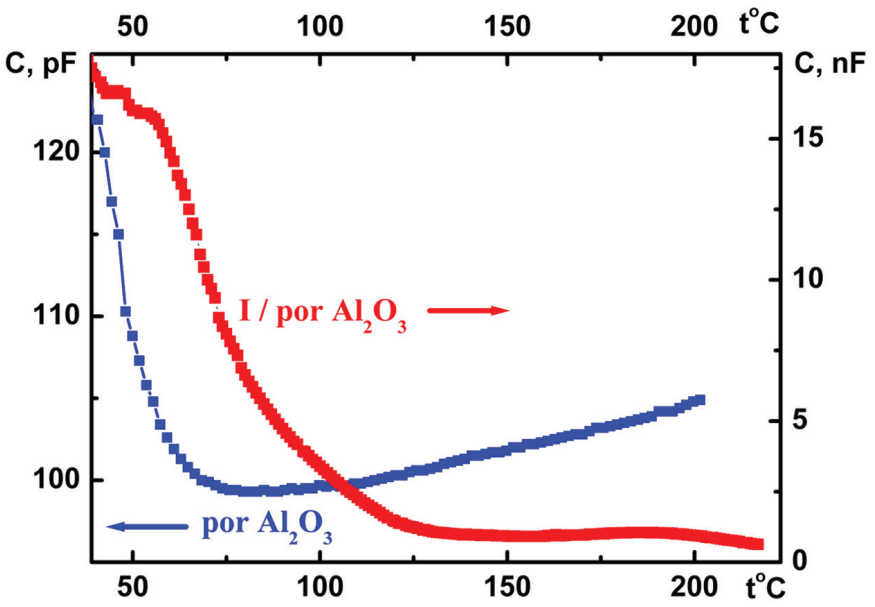

Figure 9 Temperature dependences of the electrical capacity $\mathrm{C}(\mathrm{t})$ for por $\mathrm{Al}_{2} \mathrm{O}_{3}$ host matrix and I/por $\mathrm{Al}_{2} \mathrm{O}_{3}$ nanocomposite measured at the frequency of $1 \mathrm{kHz}$.

compared with the distribution of iodine species in rather wide and disordered pores in por $\mathrm{Al}_{2} \mathrm{O}_{3}$ under study.

The measured capacity $\mathrm{C}$ value of the $\mathrm{I} /$ por $\mathrm{Al}_{2} \mathrm{O}_{3}$ nanocomposite is also $\sim 10^{2}$ times larger than that of the host matrix, but its temperature dependence $C(t)$ (Figure 9) demonstrates another peculiarity - abrupt decrease near $t_{0}$ which is typical for phase transitions accompanied by destruction of conducting percolation clusters $[15,16]$. The low-temperature peculiarities which could be observed at $t \approx 50{ }^{\circ} \mathrm{C}$ for initial por $\mathrm{Al}_{2} \mathrm{O}_{3}$ matrix are probably caused by adsorption - desorption of water molecules [17].

Thus, one can suppose that the same phase (or structural) transition occurs in $\mathrm{I} /$ por $\mathrm{Al}_{2} \mathrm{O}_{3}$ nanocomposite at $t_{0} \approx 70{ }^{\circ} \mathrm{C}$, in spite of pore arrangement irregularity and rather wide size distribution of pore diameter in the host matrix.

\section{Conclusions}

Novel I/por $\mathrm{Al}_{2} \mathrm{O}_{3}$ nanocomposite has been prepared by infiltration of por $\mathrm{Al}_{2} \mathrm{O}_{3}$ host matrix with iodine guest substance and has been characterized by scanning electron microscopy, ellipsometry and electrical measurements. Experimental results make it possible to suppose that the phase transition of iodine species from the chain structures to molecular iodine occurs at $\sim 70^{\circ} \mathrm{C}$ in different types of host matrices possessing arrays of straight and parallel 
pores or channels with varying degrees of their regularity, uniformity as well as aspect ratio values.

\section{Acknowledgments}

The authors wish to thank Professor E. V. Charnaya for her help and fruitful discussions, O. A. Alekseev for his assistance in the assembling of the experimental setup, V. D. Kalganov for having taken the SEM images. This work was supported by the Ministry of Education and Science of Russian Federation according to the scientific project 2.4128.2011 "Complex Investigation of Physical Properties of Nanocomposites Based on Regular Porous Matrices".

\section{References}

[1] V. G. Solovyev, M. S. Ivanova, S. V. Pan'kova, S. V. Trifonov, V. L. Veisman, In Handbook of Zeolites: Structure, Properties and Applications; Ed. T. W. Wong. New York, US, 77-99 (2009).

[2] J. T. Ye, Z. K. Tang, G. G. Siu, Applied Physics Letters, 88, 073114(1-3) (2006).

[3] J. T. Ye, Y. Iwasa, Z. K. Tang, Physical Review B, 83, 193409 (2011).

[4] J. T. Ye, Fabrication and optical characterization of nanostructures formed inside zeolite single crystals. PhD Thesis. Hong Kong, $163 \mathrm{p}$. (2006).

[5] S. Khanin, V. Solovyev, S. Trifonov, V. Veisman, Smart Nanocomposites, 4, 29-36 (2013).

[6] C. T. Sousa, D. C. Leitao, M. P. Proenca, J. Ventura, A. M. Pereira, J. P. Araujo, Applied Physics Reviews, 1, 031102 (1-22) (2014).

[7] H. Masuda, K. Fukuda, Science, 268, 1466-1468 (1995).

[8] K. Nielsch, J. Choi, K. Schwirn, R. B. Wehrspohn, U. Gösele, Nano Letters, 2, 677-680 (2002).

[9] A. P. Li, F. Müller, A. Birner, K. Nielsch, U. Gösele, Journal of Applied Physics, 84, 6023-6026 (1998).

[10] N. O. Alexeeva, Journal of Physics: Conference Series, 461, 012023(1-4) (2013).

[11] V. A. Shvets, E. V. Spesivtsev, S. V. Rykhlitskii, N. N. Mikhailov, Nanotechnologies in Russia, 4, 201-214 (2009).

[12] N. Alekseeva, G. Cema, A. Lukin, S. Pan'kova, S. Romanov, V. Solovyev, V. Veisman and M. Yanikov, Journal of Self-Assembly and Molecular Electronics, 1, 209-222 (2013). 
[13] W. Lee, R. Ji, U. Gösele, K. Nielsch, Nature Materials, 5, 741-747 (2006).

[14] G. W. Kaye and T. H. Laby, Tables of Physical and Chemical Constants, London, New York, Toronto (1959).

[15] S. V. Pan'kova, V. V. Poborchii, V. G. Solov'ev, Journal of Physics: Condensed Matter, 8, L203 - L206 (1996).

[16] V. Solovyev, Y. Kumzerov, S. Khanin, Physics of regular matrix composites (Electrical and optical phenomena in nanocomposite materials based on porous dielectric matrices); Saarbrücken, DE, 2011 (in Russian).

[17] O. M. Golitsyna, S. N. Drozhdin, A. E. Gridnev, Physics of the Solid State, 54, 1961-1965 (2012).

\section{Biographies}

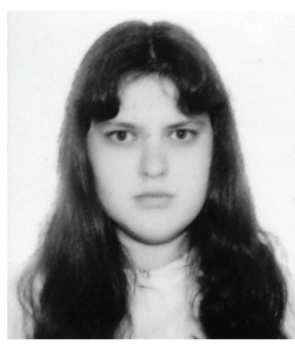

N. Alekseeva finished her post-graduate course in Solid State Physics at Pskov State Pedagogical University (Russia) in 2010. Her research activity is mostly in the fields of the scanning probe microscopy (SPM) and physics of nanostructures based on porous alumina.

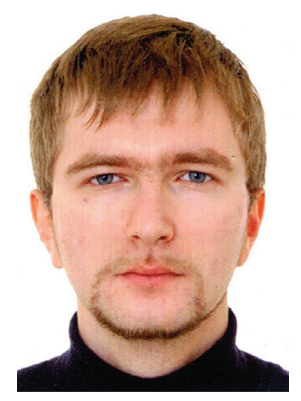

G. Cema is a third-year post-graduate student in Physics of Condensed Matter at Pskov State University (Russia). His research is focused on the study of 
optical characteristics of nanocomposite materials by photoluminescence and ellipsometry as well as on X-ray physics.

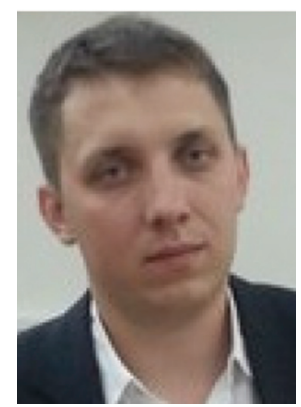

D. Podorozhkin got his diploma from Saint Petersburg State University in 2009, his PhD degree from Saint Petersburg State University (Russia, St. Petersburg) in 2014. Today he is senior specialist of Resource Centre of Saint-Petersburg State University "Centre for diagnosis of functional materials in medicine, pharmacology and nanoelectronics". His research is focused on the study of atomic mobility and phase transitions in nanocomposite materials.

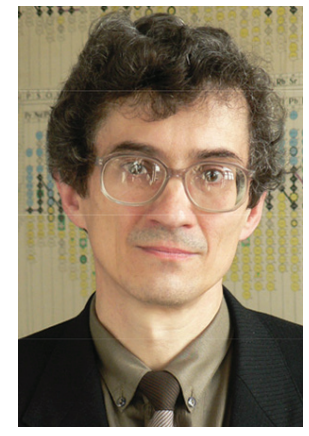

V. Solovyev got his diploma from Pskov State Pedagogical Institute (USSR) in 1976, his PhD and DSc degrees from Herzen State Pedagogical University of Russia (St. Petersburg) in 1991 and 2005. Today he is a Professor, Head of Physics Department at Pskov State University. He is the author of about 50 regular papers and 3 monographs. Major research interests focus around electrical and optical phenomena in nanocomposite materials based on regular porous dielectric matrices. 


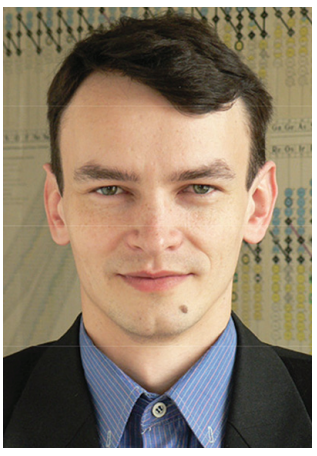

S. Trifonov graduated from Pskov State Pedagogical Institute, Physics and Mathematics faculty in 2000 and got his Ph.D. in Solid State Physics at Herzen State Pedagogical University of Russia (St. Petersburg) in 2011. Today Sergey Trifonov is Associate Professor at Pskov State University. His research interests are in methods of synthesis of zeolite-like aluminophosphates and preparation of nanocomposites based on regular porous dielectric matrices, as well as in electrical properties of zeolite-based nanocomposites.

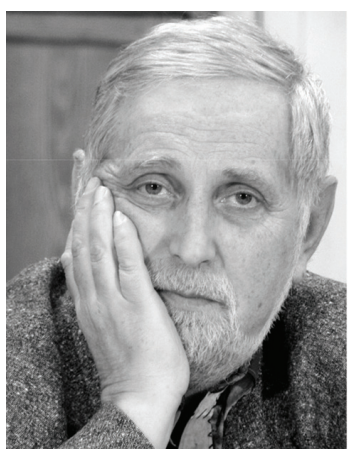

V. Veisman got his diploma from Pskov State Pedagogical Institute (USSR). Today he is Associate Professor at Pskov State University. He is the author of more than 100 regular papers, supervisor of dozens Diploma students, experienced lecturer on optics, atomic and solid state physics, quantum mechanics and astronomy. His research interests are in electrical and optical properties of point defects in alkali halide crystals, as well as in methods of preparation of nanocomposites based on regular porous dielectric matrices. 
